\title{
Investimentos em Transporte: Efeitos do Arco Metropolitano sobre o Crescimento Econômico Fluminense
}

\author{
${\text { Lucas Siqueira de } \text { Castro }^{1} \text { (D) | Carlos Otávio de Freitas }}^{2}$ (D) | Joilson de Assis Cabral ${ }^{3}$ \\ ${ }^{1}$ Universidade Federal Rural do Rio de Janeiro. E-mail: lucancastro@hotmail.com \\ 2 Universidade Federal Rural do Rio de Janeiro. E-mail: carlos.freitas87@gmail.com \\ ${ }^{3}$ Universidade Federal Rural do Rio de Janeiro. E-mail: cabraljoilson@gmail.com
}

\begin{abstract}
RESUMO
O objetivo da presente pesquisa foi identificar os efeitos do Arco Metropolitano do Rio de Janeiro sobre o crescimento econômico dos municípios do estado fluminense. Para tal, esta pesquisa propõe um procedimento metodológico capaz de mensurar o impacto de uma política pública de enfoque regional, como o investimento em infraestrutura de transporte, sobre variáveis socioeconômicas de interesse. Este procedimento consistiu em um quase-experimento integrando o pareamento por entropia com a abordagem de diferenças-em-diferenças clássica e espacial. Os resultados apontam efeitos positivos no crescimento econômico dos municípios perpassados pelo Arco, isto é, o fato de um município ter sido beneficiado pelo acesso ao Arco Metropolitano contribuiu, em média, para elevar em $21,6 \%$ seu crescimento econômico. Conclui-se que o acesso das regiões periféricas a regiões centrais e mais desenvolvidas, facilitado pelo AMRJ, pode ter contribuído para ampliar as oportunidades da população na busca por postos de trabalhos com melhor remuneração, tendo impactos significativos no crescimento econômico regional.
\end{abstract}

\section{PALAVRAS-CHAVE}

Infraestrutura de transporte, Diferenças-em-diferenças espacial, Arco Metropolitano do Rio de Janeiro

Investments in Transport: Effects of the Metropolitan Arch on Fluminense Economic Growth

\begin{abstract}
The objective of the present research was to identify the effects of the Metropolitan Arch on the economic growth of the municipalities of the State of Rio de Janeiro. To this end, this research proposes a methodological procedure capable of measuring the impact of a public policy with a regional focus, such as investments in transport infrastructure, on socioeconomic variables of interest. This procedure consisted of a quasi-experiment integrating entropy matching with the classic and spatial differences-in-differences approach. The results show positive effects on the economic growth of the municipalities affected by the Arco. That is, the fact that a municipality benefited from access to the Metropolitan Arch, contributed, on average, to increase economic growth by $21.6 \%$. It is concluded that the access of peripheral regions to central and more developed regions, facilitated by AMRJ, may have contributed to expand the opportunities of the population in the search for jobs and to better paid jobs, having significant impacts on regional economic growth.
\end{abstract}

\section{KEYWORDS}

Transportation infrastructure, Spatial difference-in-differences, Metropolitan Arch of Rio de Janeiro

\section{CLASSIFICAÇÃO JEL O18, R12, R40}




\section{Introdução}

A investigação sobre o papel exercido por investimentos em infraestrutura, sobretudo de transportes, como agentes influenciadores de desenvolvimento econômico, não é recente (Aschauer, 1989; Munnell et al., 1992). Trabalhos seminais de Von Thünen (1966); Lösch (1954); François (1955); Myrdal (1957); Hirschman (1961) mostraram, de forma direta ou indireta, a importância da capacidade de oferta e dos investimentos em transportes para as estratégias de localização das firmas e consequente adensamento industrial nas regiões dotadas desas infraestrutura. Fujita et al. (1999) resgatam e formalizam as teorias de localização sobre o que chamaram de Nova Geografia Econômica. Os autores analisam os custos de transporte e sua relação com a distribuição espacial das firmas, buscando entender o papel da infraestrutura de transporte no desenvolvimento econômico.

As externalidades positivas oriundas dos investimentos em infraestrutura de transportes podem ser de curto e longo prazo. No curto prazo, os investimentos em transportes, por mobilizarem um elevado montante de capital, podem ser entendidos como uma política expansionista, sendo capazes de gerar emprego e renda (Bueno e Sarti, 2019). No longo prazo, uma maior oferta de infraestrutura de transportes resulta na redução de custos intermediários e, consequentemente, na contração dos custos finais de produção (Krugman, 1991). Nesse sentido, a redução dos custos de transporte leva a um aumento da produtividade dos fatores de produção e da competitividade da estrutura produtiva da economia, estabelecendo uma nova dinâmica de crescimento e desenvolvimento econômico para a região (FIRJAN, 2008). A elevação da produtividade e da competitividade, ao reduzir os custos de transação, contribui também para geração de retornos maiores sobre o capital investido, estimulando a atração de investimentos internos e externos (Kroth e Dias, 2012). A infraestrutura de transporte também proporciona elevação da oferta e da produtividade da mão de obra ao garantir melhor acessibilidade ao trabalhador (Krugman, 1991), facilitar o alcance a novas tecnologias e produtos (Bank, 2006) e expandir e fortalecer os mercados regionais em função do encurtamento das distâncias e/ou do rompimento das divisas geográficas (Banister e Berechman, 2001; Berechman, 2009).

No que tange às externalidades negativas, a literatura aponta que o impacto dos investimentos em infraestrutura de transporte pode ser regionalmente desigual e prejudicial às regiões menores, que são dotadas, em sua maioria, de estrutura produtiva menos madura em detrimento das regiões centrais (Dias e Simões, 2012). Caso as regiões sejam substitutas, as regiões centrais, mais desenvolvidas e que têm certa dinâmica produtiva, se beneficiarão da integração regional via investimento em infraestrutura de transporte, levando as regiões menores a se tornarem periféricas, com pouca densidade produtiva, sem emprego e renda (Ruiz, 2006). Diante disso, a Nova Geografia Econômica mostra formalmente a possibilidade de alcançar efeitos contrários aos esperados pela realização do investimento em transporte, seja ele privado ou proveniente de uma política pública, o que se convencionou chamar de "Two-way 
Road Effects"1 (SACTRA, 1999; Puga, 2001; Holvad e Preston, 2005). Ademais, Agénor e Moreno-Dodson (2006) apontam que, havendo investimento público em infraestrutura de transportes, pode-se retardar o avanço da economia caso os agentes privados reduzam seus investimentos nesse setor, diminuindo, assim, a formação de capital no longo prazo. Diante do exposto, não há consenso acerca da direção do impacto no que tange às externalidades resultantes de investimentos e/ou melhorias na infraestrutura de transporte sobre a economia de uma região (Kelejian e Robinson, 1997). Castro (2016) ressalta que muitos trabalhos enfrentaram dificuldades empíricas para constatar a causalidade direcionada da infraestrutura, especialmente de transportes, para o crescimento econômico. A falta de consenso e as dificuldades empíricas encontradas podem ter como causas: i) a diversidade e a multidirecionalidade dos fatores que podem ser utilizados para mensurar o crescimento econômico oriundo da maior oferta de infraestrutura de transporte; ii) o uso de diferentes métodos e variáveis de interesse para captar e isolar o efeito; e iii) os modelos viesados em razão da existência de simultaneidade, ausência de controle para efeitos não observados, variáveis relevantes omitidas, erro de mensuração e heterogeneidade e/ou autocorrelação espacial (Castro, 2016).

Dada essa ressalva, torna-se relevante para a literatura empírica encontrar um método ou procedimento capaz de estimar a relação entre investimentos em infraestrutura de transporte e crescimento regional, de forma consistente e eficiente. Buscando contornar essas dificuldades e contribuir para a literatura, Castro (2016) avaliou o impacto do ProAcesso sobre o crescimento econômico dos municípios de Minas Gerais, utilizando uma combinação entre o método de diferenças em diferenças espaciais e técnicas paramétricas de matching. Todavia ressalta-se que as técnicas de pareamento utilizadas pelo autor não consideraram que as diferenças entre grupos de controle e o tratamento podem ser resultantes de desequilíbrios em outras estatísticas importantes da distribuição das variáveis, além da média amostral, como a variância e a simetria. Apresentados os desafios empíricos e a importância de mensurar os efeitos dos investimentos em infraestrutura de transportes para o desenvolvimento regional, este trabalho tem como objetivo estimar os efeitos do Arco Metropolitano do Rio de Janeiro (AMRJ) sobre o crescimento econômico dos municípios fluminenses. Para tanto, é proposto um procedimento capaz de estimar a relação teórica do efeito do investimento em infraestrutura de transporte sobre os municípios interconectados pelo AMRJ, de forma eficiente e consistente. O procedimento consiste em um quase experimento que integra a técnica de pareamento por entropia com os métodos de diferençasem diferenças clássico e espacial.

Esse procedimento avança o utilizado por Castro (2016), uma vez que o pareamento por entropia, diferentemente dos métodos de pareamento tradicionais, incorpora diretamente o equilíbrio das variáveis em uma função de peso que é aplicada às

\footnotetext{
${ }^{1}$ Políticas que objetivam conectar regiões periféricas a regiões centrais podem registrar efeitos contrários aos esperados: a transferência de renda, por exemplo, pode partir da periferia para o centro, não o contrário (SACTRA, 1999; Puga, 2001; Holvad e Preston, 2005).
} 
unidades de amostra, sem a necessidade da especificação de um modelo paramétrico probabilístico para esse fim. Além disso, o equilíbrio e a similaridade entre grupos de tratados e controle são obtidos considerando diferentes momentos amostrais (média, variância e simetria) da distribuição das variáveis, garantindo, assim, maior robustez na obtenção da amostra pareada. Ressalta-se que o procedimento metodológico proposto é capaz de mensurar o impacto de qualquer política pública de enfoque regional sobre variáveis socioeconômicas de interesse não apenas dos investimentos em infraestrutura de transportes.

O AMRJ foi idealizado em 1974 pelo governo militar, e o projeto teve seu início apenas no ano de 2008. Inaugurado em julho de 2014 a um custo de $R \$ 1,9$ bilhões, o principal objetivo da construção do Arco Metropolitano foi conectar a BR-101/NORTE com a BR-101/SUL, sem que houvesse necessidade de tráfego por vias urbanas de grandes fluxos, como a Avenida Brasil e a Ponte Costa e Silva (Ponte Rio-Niterói). Ao longo de seus 145 quilômetros de extensão, o AMRJ perpassa os municípios de Itaboraí, Guapimirim, Magé, Duque de Caxias, Nova Iguaçu, Japeri, Seropédica e Itaguaí (Brasil, 2011). Como reflexo do aumento da acessibilidade nos oito municípios da baixada fluminense relacionados, houve mudanças no comportamento dos agentes (Preston, 2001; Berechman, 2009), como a empresa de alimentos e agronegócios Bunge do Brasil e a Rolls Royce equipamentos navais, que investiram em novas instalações em Duque de Caxias. Já a Petrobrás, a Gerdau, a Companhia Siderúrgica Nacional (CSN), a Usiminas, a Marinha e a Itaguaí Construções Navais (ICN) fizeram investimentos em Itaguaí, enquanto a Procter \& Gamble fez investimentos em Seropédica.

Diante do exposto, a escolha do AMRJ para a aplicação do método proposto deveuse à importância dessa infraestrutura para o estado do Rio de Janeiro, ao fato de o empreendimento percorrer municípios menores e menos desenvolvidos com índices de desenvolvimento socioeconômicos similares, sendo capaz de estimar o possível efeito de "Two-way Road Effects", e ao fato de o AMRJ representar uma variação exógena na infraestrutura de transporte do Rio de Janeiro, o que garante a hipótese de identificação do resultado de como a infraestrutura de transporte afeta o crescimento econômico de forma consistente e eficiente. A escolha do AMRJ também foi devido à complexidade de identificação dos resultados dos estudos que utilizam municípios em suas análises quando comparados aos trabalhos que analisaram países. Essa complexidade decorre do fato de as cidades terem livre mobilidade dos fatores de produção, podendo apresentar uma dependência espacial na análise empreendida. Para controlar esse problema, a análise empreendida para municípios deve utilizar técnicas capazes de modelar corretamente a possivel dependência espacial existente, caso do procedimento metodológico proposto no presente trabalho. Dessa forma, a aplicação empírica proposta contribui para a literatura de avaliação de políticas públicas de investimento em infraestrutura de transportes. Por fim, ressalta-se que não foram encontrados trabalhos que avaliaram o AMRJ. 
Além dessa seção introdutória, o presente trabalho está estruturado como segue. Na próxima seção, é apresentada uma revisão de literatura selecionada acerca do tema. A terceira seção apresenta a estratégia empírica adotada para avaliar o impacto do AMRJ no PIB dos municípios fluminenses. Na sequência, são discutidos os resultados obtidos, finalizando com as conclusões.

\section{Infraestrutura de transportes e crescimento econômico}

Tendo como referência trabalhos como o de (Aschauer, 1989), a literatura apresenta estudos que tentaram mensurar o impacto do investimento público, sobretudo a infraestrutura de transportes, no crescimento econômico. A estruturação desta revisão de literatura selecionada, portanto, será feita informando as técnicas e os resultados alcançados pelos autores ${ }^{2}$. Shah (1992), por meio do equilíbrio restrito, estimou a contribuição do investimento público em infraestrutura no lucro do setor privado mexicano entre 1970 e 1987. A função de custo translog desenvolvida pelo autor conseguiu fragmentar a modalidade de investimentos do setor público nas pautas de transporte, comunicação e energia elétrica. Apesar da pequena magnitude, o impacto do investimento em infraestrutura de transporte foi positivo.

Ferreira e Malliagros (1996b); Malliagros (1997); Ferreira e Malliagros (1996a), por meio de modelos de Vetores de Cointegração, detectaram que investimentos em infraestrutura de transportes afetam de maneira significativa o PIB brasileiro, considerando a elasticidade de renda. Ferreira (1996) reforça que o baixo crescimento do país entre 1970 e 1993 se deu em função da queda dos investimentos em infraestrutura.

Sturm et al. (1999) estudaram o impacto do investimento em infraestrutura de transporte no PIB holandês no período entre 1853 e 1913. Os resultados estimados por vetores autorregressivos (VAR) estabeleceram, no curto e no médio prazo, impactos positivos do investimento em transporte sobre o crescimento do PIB. Rocha e Giuberti (2007) examinaram a relação entre os componentes do gasto público e o crescimento econômico de longo prazo nos estados brasileiros. Dispondo de um painel de dados (1986 a 2002) e utilizando um modelo de efeitos fixos, os autores registraram que as despesas com infraestrutura de transportes apresentaram, além da significância estatística, coeficientes positivos.

Crescenzi e Rodríguez-Pose (2008) pesquisaram como o investimento em infraestrutura, especialmente a de transportes, afetou o crescimento/desenvolvimento regional na Europa no período entre 1990 e 2003. Tendo como base modelos de dados em painel de efeitos fixos, observou-se que os investimentos em infraestrutura de transporte podem beneficiar regiões centralizadas em detrimento das periféricas. As respostas encontradas por Crescenzi e Rodríguez-Pose (2008) reforçam o "Two-way Road Effects” (SACTRA, 1999; PUGA, 2001; PRESTON e HOLVAD, 2005).

\footnotetext{
${ }^{2}$ Os autores informam que não cabe a esta seção exaurir o tema analisado, mas tão somente evidenciar as possiveis lacunas a serem preenchidas por este trabalho, além de auxiliar na interpretação dos resultados.
} 
Cruz et al. (2010) verificaram os efeitos dos gastos públicos em infraestrutura no crescimento econômico e na redução da pobreza no Brasil entre os anos de 1980 e 2007. Por meio de equações simultâneas, os autores comprovaram a eficiência dos gastos públicos em educação, saúde, estradas e energia. De maneira geral, os avanços elevaram a renda per capita e a produtividade total dos fatores, gerando crescimento econômico, com redução da pobreza.

Amarante (2011), fazendo uso da modelagem de dados em painel, verificou o impacto da pavimentação das BR 101 e BR1 16 no crescimento econômico dos municípios catarinenses entre 1970 e 2006. Em média, constatou-se maior crescimento/desenvolvimento econômico dos municípios cortados pelas rodovias ao longo do período predeterminado.

Guimarães (2012) analisou possiveis relações entre infraestrutura e convergência de renda no Brasil no período de 1999 e 2005. Empregando modelos hierárquicos espaciais, cujas bases são os níveis estadual e municipal, o autor constata que o estoque de infraestrutura rodoviária foi significativo na determinação do processo de convergência.

Badalyan et al. (2014) buscaram entender a relação (causalidade) entre infraestrutura de transporte, investimento em infraestrutura e crescimento econômico para os países da Armênia, Turquia e Georgia. Mediante estimação de painéis, com dados entre 1982 e 2010, os autores atestaram existência de causalidade bidirecional entre crescimento econômico e investimento em infraestrutura de transporte no curto e no longo prazo.

Castro (2016) avaliou o impacto do Programa de Pavimentação de Ligações e Acessos aos Municípios (ProAcesso) no crescimento econômico dos municípios mineiros beneficiados por esse programa entre 2000 e 2010. Para tanto, o autor construiu seu modelo, combinando o método de diferenças em diferenças espaciais com técnicas de pareamento (kernel e $n$ vizinhos mais próximos). Como resposta, viu-se que, independentemente da forma de avaliação feita, considerando o resultado sobre o PIB per capita geral, setorial, ou mesmo alterando a mensuração de variável de interesse (binária ou considerando o total de quilômetros pavimentados por município), o fato de um município ser atendido pelo ProAcesso não resultou em maior crescimento econômico.

Silva et al. (2016) buscaram medir os efeitos dos investimentos em infraestrutura de transporte, realizados pelo Programa de Aceleração do Crescimento (PAC), sobre a dinâmica regional brasileira. Dispondo de dados entre os anos de 1986 e 2009, os autores aplicaram técnicas de painéis e bootstrapping para as estimativas e predições realizadas. Os resultados indicaram que o PAC não auxiliou o aumento da taxa média de crescimento dos PIBs estaduais brasileiros nem reduziu as desigualdades regionais existentes. Gueiroz e Fernandes (2018) investigaram a relação entre os investimentos em infraestrutura de transportes e o crescimento econômico brasileiro entre os anos 
de 2008 e 2013. Como mecanismo, foi implementado um modelo de dados em painel de efeitos fixos para as 27 unidades da federação e se chegou à conclusão de que o processo de crescimento econômico pode ser considerado multicausal, dadas as interações geográficas (spillovers - $\mathrm{P} \& \mathrm{D}$, dotação e investimentos em infraestrutura). Foi visto também que uma maior oferta de conexões rodoviárias, associadas aos spillovers de investimentos em transporte, afetou positivamente o crescimento econômico.

Cigu et al. (2019) mediram os efeitos da ligação entre a infraestrutura de transporte e o desempenho econômico em 28 países europeus, entre 2000 e 2014, usando a metodologia de dados em painel. Foram encontrados pelos autores efeitos significativos dos componentes da infraestrutura de transporte no desempenho econômico, mesmo após o controle de fatores institucionais.

Por fim, Ke et al. (2020), usando um sistema de dados de painel dinâmico (GMM), encontraram fortes evidências de que a infraestrutura de transporte contribuiu para o crescimento econômico regional na China durante o período de 2007 a 2015. Para os autores, a melhoria da qualidade das estradas e das ferrovias, interligada à atualização estrutural da infraestrutura de transporte, contribuiu significativamente para o crescimento chinês. Esta seção realizou um levantamento bibliográfico dos trabalhos que avaliaram a relação entre investimentos em infraestrutura de transportes e crescimento econômico. O Guadro A1, em anexo, resume os trabalhos apresentados.

Por meio desta revisão, é possível perceber que o presente trabalho contribui para a literatura de avaliação de políticas em dois aspectos: i) para a literatura de Economia Regional, ao avaliar a importância do AMRJ para o crescimento dos municípios fluminenses; e ii) para a literatura empírica, ao propor um procedimento metodológico sem e com controle espacial ${ }^{3}$, capaz de mensurar o impacto de qualquer política pública de enfoque regional sobre variáveis socioeconômicas de interesse, não apenas dos investimentos em infraestrutura de transportes. O objetivo do procedimento é estimar de forma consistente e eficiente o efeito causal da política por meio de um grupo de controle e tratamento equilibrado.

\section{Estratégia Empirica}

A definição pela estratégia empírica a ser desenvolvida deve ponderar sobre como a política pública avaliada impacta no desempenho econômico dos municípios de interesse. No caso do Arco Metropolitano do Rio de Janeiro, a princípio, quatro são as ponderações levantadas que influenciam na identificação do efeito desejado: mudanças no comportamento dos agentes produtivos, ocorridas de maneira exógena (em função do acesso ao Arco Metropolitano); externalidades de rede, causando dependência espacial (o impacto do AMRJ pode ultrapassar as divisas dos municípios beneficiados diretamente); influência de características não observadas que não variam no

\footnotetext{
${ }^{3}$ Até o final da elaboração deste artigo, não foram encontrados na literatura trabalhos que realizassem tal procedimento metodológico.
} 
tempo; e influência de fatores observáveis visualizados antes da construção do AMRJ (que possam ter interferido na determinação dos municípios a serem beneficiados pela construção do AMRJ).

Na tentativa de resolver esses problemas, é proposto um procedimento metodológico integrando a técnica de pareamento por entropia e os modelos de diferenças em diferenças, com e sem controle espacial. Por meio da técnica de pareamento por entropia, é possível compor um grupo de controle ponderado por pesos obtidos pelas características observáveis do grupo de tratamento, considerando diferentes momentos amostrais da distribuição dessas variáveis. Dessa maneira, espera-se que ambos os grupos, controle e tratamento, sejam formados por municípios com características semelhantes, conforme orientado por Becker e Ichino (2002).

A saída para controlar as características não observáveis, invariantes no tempo, provém da utilização das diferenças em diferenças, visto que a própria metodologia expurga os efeitos fixos invariantes no tempo. A existência da autocorrelação espacial inviabiliza a garantia da hipótese de identificação SUTVA (Stable-Unit-Treatment-Value Assumption), apontada por Rubin (1977), além de quebrar a premissa de independência condicional. Essas duas premissas subjacentes são necessárias para que o modelo convencional de diferenças em diferenças estime de forma consistente e eficiente o efeito causal (Castro, 2016; Cabral, 2016) do impacto do AMRJ sobre crescimento econômico dos municípios fluminenses.

Caso a autocorrelação espacial seja comprovada, as premissas estabelecidas anteriormente não são garantidas, não sendo possível identificar o efeito da política analisada (Cabral, 2016). No caso do investimento em infraestrutura analisado, é possível que exista absorção de efeitos indiretos por municípios pertencentes ao grupo de controle, vizinhos de municípios que tenham sido beneficiados com o acesso ao AMRJ (grupo de tratamento). Uma forma de contornar esse problema é estimar um modelo de diferenças em diferenças espacial (Dubé et al., 2014; Cabral, 2016). Esae método é capaz de modelar a dependência espacial, ou seja, transbordamentos dos efeitos do AMRJ em municípios vizinhos, pertencentes ou não ao grupo de tratamento, estimando o efeito médio do impacto do AMRJ sobre o crescimento econômico dos municípios fluminenses de forma consistente e eficiente (Chagas et al., 2016; Castro, 2016; Cabral, 2016).

\subsection{Pareamento por Entropia}

No presente trabalho, busca-se obter uma amostra "pareada" equilibrada, isto é, uma amostra com unidades de controle mais próximas possiveis das unidades de tratamento (municípios cortados pelo AMRJ), com base em um vetor de características observáveis. Para tal, utilizou-se o método do balanceamento por entropia, proposto por Hainmueller (2012). Diferentemente das abordagens tradicionais de pareamento, o balanceamento por entropia envolve um esquema de reponderação que incorpora diretamente o equilíbrio da covariável na função de peso, que é incorporada às uni- 
dades amostrais consideradas. De modo geral, o método do pareamento por entropia trata de uma abordagem não paramétrica na qual um grupo de covariadas são ponderadas, permitindo que as distribuições das variáveis nas observações reponderadas atendam a um conjunto de condições especiais de momentos, garantindo, assim, um equilíbrio. Além disso, o equilíbrio é mantido mesmo quando diferentes momentos das distribuições de tais variáveis são considerados (Hainmueller, 2012). Nessa abordagem, ao invés de especificar um modelo paramétrico que explique a probabilidade de participação no tratamento, a exemplo do propensity score e outros, os pesos são estimados e direcionados a cada unidade de controle, de modo que os grupos de tratados e controle, após ponderados, satisfaçam um conjunto de restrições de equilíbrio. As restrições são impostas sobre os três possiveis momentos amostrais (média, variância e assimetria) das distribuições das covariadas e, ao assegurar a similaridade dos momentos entre os grupos ponderados, garantirão o equilíbrio entre a amostra de controle e o tratamento.

A restrição de momento utilizada nesta pesquisa refere-se à imposição de que o primeiro momento das covariadas seja ajustado ${ }^{4}$. Desta forma, para todas as covariadas, o método calcula as médias no grupo de tratamento e busca por um conjunto de pesos de entropia tal que as médias ponderadas do grupo de controle sejam similares. Esses pesos são utilizados nas etapas seguintes, obtendo, assim, estimativas livres do viés causado pelas características observáveis pré-tratamento. Consequentemente, o grupo de controle foi formado pelos 83 municípios fluminenses que não são conectados diretamente ao Arco Metropolitano ${ }^{5}$, com base nas características observáveis da amostra antes da construção do AMRJ. A Figura 1 mostra o arranjo geográfico dos grupos de controle e de tratamento.

\subsection{Método de diferenças em diferenças espacial (SDID)}

O método de diferenças em diferenças convencional (DID) implementa uma dupla diferença da variável dependente nos grupos de tratamento e controle. Cameron e Trivedi (2005) e Wooldridge (2017) reforçam que, havendo dois períodos, representados neste trabalho, a partir da construção do Arco Metropolitano, ou seja, antes e depois do AMRJ, o efeito médio do tratamento pode ser determinado por uma equação em primeiras diferenças $(\Delta)$ :

$$
\Delta P I B_{i t}=\alpha+\theta \Delta A M R J_{i t}+\Delta X_{i t} \beta+\Delta \varepsilon_{i t}
$$

\footnotetext{
${ }^{4} \mathrm{O}$ balanceamento por entropia permite que até os três momentos amostrais sejam aplicados simultaneamente. No entanto, por se tratar de uma amostra relativamente pequena, 83 unidades de controle e 8 unidades tratadas, optou-se por aplicar o método apenas para a média amostral, permitindo que, mesmo com esse número de observações, o modelo seja capaz de identificar pesos que consigam, de fato, gerar uma amostra equilibrada entre controle e tratados.

${ }^{5} \mathrm{O}$ município do Rio de Janeiro foi excluído da amostra por se tratar de um outlier, sobretudo nas variáveis empregadas no pareamento, como empregos, densidade demográfica e taxa de homicídios.
} 


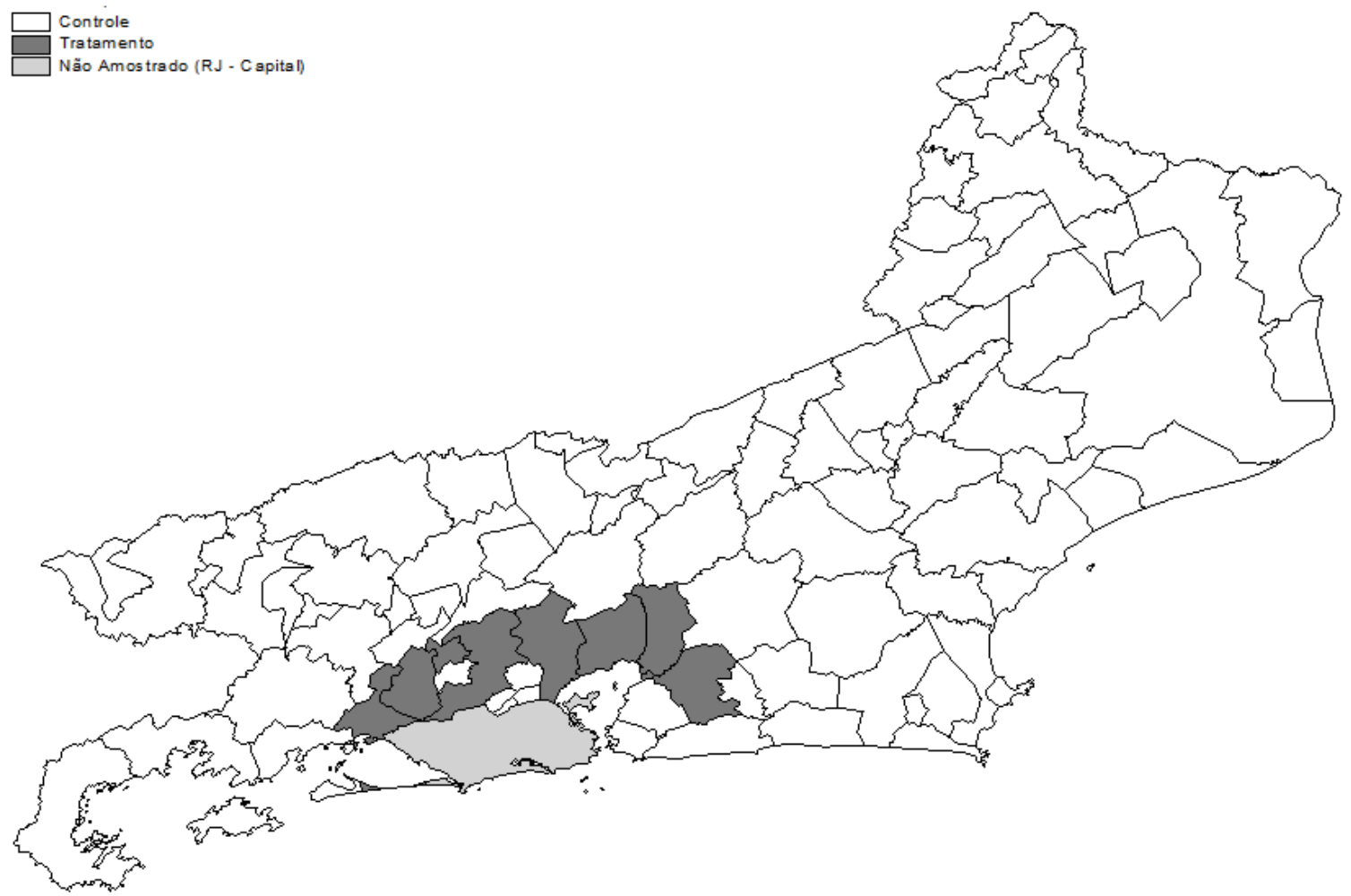

Figura 1. Arranjo geográfico dos grupos de controle e tratamento. Fonte: elaborado pelo autor.

Em que $P I B$ corresponde à taxa de crescimento do PIB per capita dos municípios fluminenses; $A M R J$ representa a dummy do Arco Metropolitano do Rio de Janeiro; $X$ denota o vetor de variáveis controle; e $\varepsilon$ é o termo de erro. $\alpha, \theta$ e $\beta$ são os coeficientes a serem estimados. Finalmente, o subscrito $i$ faz alusão ao município determinado, ao passo que $t$ remete ao tempo.

Caso o pressuposto SUTVA não seja garantido, os efeitos causais do AMRJ podem não ser reconhecidos, considerando sua possível influência em municípios vizinhos, tratados ou não tratados, não sendo possivel identificar o efeito do AMRJ sobre o crescimento econômico dos municípios. Dessa forma, quando não é possivel garantir a hipótese SUTVA e a premissa de média condicional, é possivel inferir a ocorrência de transbordamentos espaciais entre os municípios tratados e não tratados, tornando-se necessário adicionar a defasagem da variável dependente $\left(W \Delta P I B_{i t}\right)$.

Convém atentar para o fato de que o AMRJ também pode se apresentar espacialmente autocorrelacionado, sendo necessário inserir a defasagem espacial do AMRJ $\left(W \Delta A M R J_{i t}\right)$. Em outras palavras, é possivel que o ARMJ, além de impactar os municipios interconectados por ele, também influencie municípios que não foram diretamente beneficiados pela política. Ainda é possivel haver influências das variáveis de controle e dos efeitos não observados autocorrelacionados espacialmente que variam no tempo, mas não correlacionados com o AMRJ. Para controlá-los, devem ser incluídas no modelo defasagens espaciais do tipo $W \Delta X_{i t} \tau$ e $W \Delta \xi_{i t}$, respectivamente. 
Logo, o modelo geral de diferenças em diferenças espaciais, ponderado pelos pesos de entropia obtidos na primeira etapa da estratégia empírica apresentada, pode ser reestruturado pela inserção das defasagens espaciais em (1):

$$
\begin{gathered}
\Delta P I B_{i t}=\alpha+\theta \Delta A M R J_{i t}+\phi W \Delta A M R J_{i t}+\rho W \Delta T X P I B_{i t}+\Delta X_{i t} \beta+W \Delta X_{i t} \tau+\Delta \xi_{i t} \\
\Delta \xi_{i t}=\lambda W \Delta \xi_{i t}+\Delta \varepsilon_{i t}
\end{gathered}
$$

em que $\theta, \phi, \beta, \theta$ e $\lambda$ são coeficientes a serem estimados.

As especificações dos modelos SDID podem ser obtidas pela imposição de restrições aos parâmetros das equações (2a) e (2b). Determinando que $\phi=\tau=\lambda=0$ e $\rho \neq 0$, alcança-se o modelo SDID-SAR (defasagem espacial da variável dependente); $\operatorname{com} \phi=$ $\rho=\tau=0$ e $\lambda \neq 0$, atinge-se o modelo SDID-SEM (defasagem espacial do termo de erro); com $\lambda=0, \phi \neq 0, \rho \neq 0$ e $\tau \neq 0$, obtém-se o modelo SDID-SDM (defasagem espacial da variável dependente e das variáveis de controle); com $\rho=0, \phi \neq 0, \tau \neq 0$ e $\lambda \neq 0$, estima-se o modelo SDID-SDEM (defasagem espacial do termo de erro e das variáveis de controle); e, finalmente, $\operatorname{com} \rho=\lambda=0, \phi \neq 0$ e $\tau \neq 0$, tem-se o modelo SDID-SLX (defasagem espacial das variáveis de controle) ${ }^{6}$.

Testes de dependência espacial considerados difusos, como o I de Moran ou $c$ de Geary, podem ser aplicados aos resíduos do modelo DID padrão, com o objetivo de verificar aspectos da autocorrelação espacial. Por sua vez, testes focados, como o do multiplicador de Lagrange e suas versões robustas, propõem o tipo de defasagem espacial a ser incluída na regressão estimada ${ }^{7}$.

\subsection{Dados}

Em termos de dados, foram empilhadas variáveis relacionadas aos 91 municípios do estado do Rio de Janeiro para os anos de 2007, anteriores às obras do Arco Metropolitano, e de 2015, após sua construção.

O PIB per capita é a variável dependente. A variável de interesse (AMRJ) foi elaborada na forma de uma variável binária (dummy). Assim, municípios cortados pelo AMRJ, grupo de tratamento, receberam o valor 1. Já o valor 0 foi atribuído aos municípios sem acesso direto ao AMRJ, grupo de controle. Como controle, foram utilizadas as seguintes variáveis socioeconômicas: níveis de capital físico e capital humano, quantidade de empregos formais, gasto municipal com saúde, densidade demográfica e taxa de homicídios. O Quadro 1 resume as fontes e unidades das variáveis utilizadas no modelo empírico estimado.

\footnotetext{
${ }^{6}$ Naturalmente, caso todos os parâmetros espaciais da equação (2) se apresentem nulos, a estimação deve ser feita pela técnica DID padrão.

${ }^{7}$ Mais informações sobre os testes e modelos espaciais citados podem ser encontradas em Moran (1948); Anselin (1995) e Lesage e K. (2009).
} 
Quadro 1. Descrição das variáveis utilizadas

\begin{tabular}{|c|c|c|c|c|c|}
\hline Variável & $\begin{array}{l}\text { Tipo de Va- } \\
\text { riável }\end{array}$ & Descrição & Unidades de Medida & Referências & Fonte \\
\hline PIB & Dependente & PIB per capita & $\mathrm{R} \$$ & (Solow, 1956) & IBGE \\
\hline AMRJ & Interesse & Dummy AMRJ & $\begin{array}{l}\mathrm{DP}=1 \text { para o grupo de } \\
\text { tratamento e } \mathrm{DP}=0 \text { para } \\
\text { o grupo controle }\end{array}$ & & $\begin{array}{l}\text { Elaborada } \\
\text { pelos } \mathrm{Au}- \\
\text { tores }\end{array}$ \\
\hline $\mathrm{CF}$ & Pareamento & $\begin{array}{l}\text { Capital Físico } \\
\text { per capita }\end{array}$ & $\begin{array}{l}\text { Quantidade de veículos } \\
\text { automotores produtivos / } \\
\text { População }\end{array}$ & $\begin{array}{l}\text { (Solow, 1956; } \\
\text { Castro, 2016) }\end{array}$ & DENATRAN \\
\hline $\mathrm{CH}$ & Pareamento & $\begin{array}{ll}\text { Capital } & \mathrm{Hu}- \\
\text { mano } & \text { per } \\
\text { capita } & \end{array}$ & $\begin{array}{l}\left.\text { IDEB (4 }{ }^{\mathrm{a}} \text { série } / 5^{\circ} \text { ano }\right)- \\
\text { calculado tendo como } \\
\text { base dados sobre apro- } \\
\text { vação escolar, obtidos } \\
\text { no Censo Escolar, e as } \\
\text { médias de desempenho } \\
\text { nas avaliações do Inep } \\
\text { para os municípios. }\end{array}$ & $\begin{array}{l}\text { (Lucas Jr, } \\
\text { 1988; Mankiw } \\
\text { et al., 1992; } \\
\text { Silva et al., } \\
\text { 2016) }\end{array}$ & INEP \\
\hline EMP & Pareamento & $\begin{array}{l}\text { Total de vín- } \\
\text { culos ativos } \\
\text { nos municí- } \\
\text { pios }\end{array}$ & Quantidade & $\begin{array}{lr}(\mathrm{Cruz} & \text { et al., } \\
2010 ; & \text { Cam- } \\
\text { pos } & \text { Neto, } \\
2014) & \end{array}$ & $\begin{array}{l}\text { CAGED/ } \\
\text { MTE }\end{array}$ \\
\hline SAP & Pareamento & $\begin{array}{ll}\text { Gasto } & \text { per } \\
\text { capita } & \text { mu- } \\
\text { nicipal } & \text { com } \\
\text { saúde } & \end{array}$ & $\mathrm{R} \$$ & $\begin{array}{l}\text { (Barro, 1996; } \\
\text { Silva et al., } \\
2016)\end{array}$ & FINBRA \\
\hline DENS & Pareamento & $\begin{array}{l}\text { Densidade de- } \\
\text { mográfica }\end{array}$ & População/KM ${ }^{2}$ & $\begin{array}{l}\text { (Fujita et al., } \\
\text { 2002; Ke } \\
\text { et al., 2020) }\end{array}$ & IBGE \\
\hline $\mathrm{HOM}$ & Pareamento & $\begin{array}{l}\text { Taxa de homi- } \\
\text { cídios }\end{array}$ & $\begin{array}{l}\text { [Número de óbitos de resi- } \\
\text { dentes por agressões / Po- } \\
\text { pulação] * } 100.000\end{array}$ & $\begin{array}{l}\text { (Khan, 1998; } \\
\text { Castro, 2016) }\end{array}$ & $\begin{array}{l}\text { DATASUS/ } \\
\text { MS }\end{array}$ \\
\hline
\end{tabular}

Fonte: Elaborado pelo autor.

Como pode ser observado pelo Quadro 1, tanto a especificação econométrica quanto a definição das variáveis de interesse e controle tiveram como como base a literatura, que relaciona crescimento econômico com investimentos em infraestrutura de transporte.

\section{Resultados}

Esta seção está estruturada em três subseções. A primeira subseção apresenta a descrição das variáveis utilizadas, bem como o resultado do pareamento por entropia. A segunda subseção faz o estudo exploratório dos dados de maneira espacial. Caso seja encontrada autocorrelação espacial, por exemplo, o modelo a ser desenvolvido deve levar em consideração formas de eliminar o problema, tendo como referência as interações espaciais, uma vez que a hipótese SUTVA não pode ser garantida. Por fim, a terceira subseção trata de discutir o impacto do AMRJ sobre o crescimento econômico 
dos municípios fluminenses.

\subsection{Análise descritiva e pareamento por entropia}

Antes de apresentar os resultados referentes aos efeitos do AMRJ no crescimento econômico dos municípios considerados, é feita uma análise descritiva das variáveis consideradas na pesquisa, desagregadas para seus respectivos anos. A Tabela 1 mostra que a média do PIB per capita da amostra considerada foi de R\$ 21.678,3 antes da criação do arco metropolitano (2007) e de R\$ 34.062,1 em 2015, período após a criação do AMRJ. Quando considerados separadamente os municípios atendidos e não atendidos pelo AMRJ, observa-se que a média do segundo grupo é relativamente maior nos dois períodos analisados. No entanto, o grupo de municípios atendidos pelo arco apresentou maior crescimento do PIB per capita médio no período após o surgimento do arco, passando de R\$ 13.214,1 em 2007 para uma média de R\$ 26.388,5 em 2015. $\mathrm{O}$ alto desvio-padrão identificado na amostra ainda comprova grande heterogeneidade na distribuição da variável representativa da renda (Tabela 1).

Quanto às demais variáveis consideradas, os dados da Tabela 1 mostram que os municípios localizados no entorno do arco têm, em média, maiores níveis de emprego (EMP), capital físico (CF), número de homicídios (HOM) e densidade populacional (DENS). Já os municípios não cortados pelo arco apresentam níveis de capital humano relativamente superiores aos demais nos dois períodos considerados. Destacam-se ainda o aumento significativo dos níveis de emprego (EMP), o capital físico (CF) e o gasto com saúde (SAP) dos municípios atendidos pelo AMRJ, comparando os períodos antes e após a criação do empreendimento.

A Tabela 2 apresenta o resultado do pareamento da amostra pelo método da entropia. Assim como mencionado na seção 3, o pareamento foi feito considerando o primeiro momento da amostra, isto é, a média das variáveis utilizadas. É possível notar que, antes da realização do procedimento de entropia, as médias entre os grupos dos tratados (municípios cortados pelo AMRJ) e controle (municípios não cortados pelo AMRJ) apresentavam diferenças significativas ${ }^{8}$. No entanto, após feito o balanceamento por entropia, observa-se equilíbrio entre as médias, indicando que o método foi capaz de gerar pesos de modo que, para cada unidade tratada, haverá um contrafactual similar, diferenciando-se pelo fato de ser atendido ou não pelo AMRJ. Tais pesos são incorporados às estimações realizadas ${ }^{9}$.

\footnotetext{
${ }^{8}$ Tais diferenças foram estatisticamente confirmadas pelo teste de diferença de médias.

${ }^{9} \hat{\mathrm{E}}$ importante mencionar que o balanceamento que melhor se ajustou à amostra considerada não incorporou a variável relativa ao número de homicídios (Hom). Sendo assim, mesmo controlando para o viés gerado pelas diferenças em observáveis das demais variáveis consideradas, as diferenças relativas ao número de homicídios podem representar uma possível fonte de viés.
} 
Tabela 1. Análise Descritiva das variáveis utilizadas antes e após a implementação do Arco Metropolitano

Antes do Arco Metropolitano (2007)

\begin{tabular}{lcc|cc|cc} 
& \multicolumn{2}{c}{ Amostra Total } & \multicolumn{2}{c}{ Municípios Arco } & \multicolumn{2}{c}{ Municípios Não Arco } \\
\hline Variáveis & Média & Desvio padrão & Média & Desvio padrão & Média & Desvio padrão \\
\hline PIB & $21.678,3$ & $36.001,97$ & $13.214,1$ & $9.769,829$ & $22.448,4$ & $37.735,6$ \\
DENS & 629.835 & $1.833,196$ & 794,75 & 6.368 .208 & 604.342 & $1.920,488$ \\
EMP & $16.387,7$ & $28.599,47$ & $36.608,4$ & $48.100,96$ & $13.890,2$ & $25.284,62$ \\
SAP & 396.965 & 2.731 .538 & 217.805 & 7.529 .061 & 414,41 & 2.809 .538 \\
CF & $1.591,75$ & $2.371,461$ & $3.641,88$ & $4.046,412$ & $1.352,84$ & $2.057,971$ \\
CH & 418.791 & 0,4394024 & 3,7 & 0,1603568 & 424.146 & 0,4277276 \\
HOM & 278.298 & 2.139 .641 & 488.338 & 1.933 .089 & 25.705 & 2.068 .243 \\
$N$ & 91 & & 8 & & 83 \\
\hline
\end{tabular}

Após o Arco Metropolitano (2015)

\begin{tabular}{lcc|cc|cc} 
& \multicolumn{2}{c}{ Amostra Total } & \multicolumn{2}{c}{ Municípios Arco } & \multicolumn{2}{c}{ Municípios Não Arco } \\
\hline Variáveis & Média & Desvio padrão & Média & Desvio padrão & Média & Desvio padrão \\
\hline PIB & $34.062,8$ & $30.919,76$ & $26.388,5$ & $16.908,75$ & $34.802,5$ & $31.915,46$ \\
DENS & 653.071 & $1.832,071$ & 835.294 & 6.364 .701 & 635.508 & $1.909,402$ \\
EMP & $21.182,7$ & $35.864,69$ & $48.869,9$ & $58.384,21$ & 18,514 & $32.230,12$ \\
SAP & $1.003,11$ & 5.900 .256 & 609.345 & 362.332 & $1.041,07$ & 5.952 .325 \\
CF & $3.344,98$ & $4.795,051$ & $8.335,75$ & $8.772,503$ & $2.863,94$ & $4.000,245$ \\
CH & 513.187 & 0,5120502 & 46.125 & 0,2167124 & 518.193 & 0,5048894 \\
HOM & 23,91 & 1.690 .573 & 433.838 & 1.231 .988 & 22.033 & 1.612 .967 \\
$N$ & 91 & & & & 8 \\
\hline \hline
\end{tabular}

Fonte: Resultados da pesquisa.

Obs: PIB - PIB per capita; DENS - Densidade; EMP - Empregos; SAP - Gasto Municipal de Saúde; CF

- Capital Físico; CH - Capital Humano; HOM - Taxa de Homicídios. 
Tabela 2. Resultado do pareamento por entropia

\begin{tabular}{|c|c|c|c|c|c|c|}
\hline \multicolumn{7}{|c|}{ Antes do Balanceamento por Entropia } \\
\hline \multicolumn{4}{|c|}{ Tratamento } & \multicolumn{3}{|c|}{ Controle } \\
\hline Covariadas & Média & Variância & Assimetria & Média & Variância & Assimetria \\
\hline DENS & 794,80 & 405,54 & 0,59 & 604,30 & $3.688 .274,00$ & $4.688,00$ \\
\hline EMP & 36,61 & $2.310 .000 .000,00$ & $1.377,00$ & 13,89 & $639.000 .000,00$ & $3.437,00$ \\
\hline SAP & 217,80 & $5.669,00$ & 0,83 & 414,40 & $78.935,00$ & $2.597,00$ \\
\hline $\mathrm{CF}$ & 3,64 & $16.400 .000,00$ & 0,92 & 1,35 & $4.235 .244,00$ & $2.271,00$ \\
\hline $\mathrm{CH}$ & 3,70 & 0,03 & 0,67 & $4.241,00$ & 0,18 & 0,10 \\
\hline \multicolumn{7}{|c|}{ Após o Balanceamento por Entropia } \\
\hline & \multicolumn{3}{|c|}{ Tratamento } & \multicolumn{3}{|c|}{ Controle } \\
\hline Covariadas & Média & Variância & Assimetria & Média & Variância & Assimetria \\
\hline DENS & 794,80 & 405,54 & 0,59 & 794,50 & $1.978 .546,00$ & $1.463,00$ \\
\hline EMP & 36,61 & $2.310 .000 .000,00$ & $1.377,00$ & 36,59 & $3.520 .000 .000,00$ & 1,44 \\
\hline SAP & 217,80 & 5,67 & 0,83 & 217,80 & 11,52 & $1.036,00$ \\
\hline $\mathrm{CF}$ & 3,64 & $16.400 .000,00$ & 0,92 & 3,64 & $11.800 .000,00$ & 0,65 \\
\hline $\mathrm{CH}$ & 3,70 & 0,03 & 0,67 & 3,70 & 0,09 & 0,35 \\
\hline
\end{tabular}

Fonte: Resultados da pesquisa.

Obs: DENS - Densidade; EMP - Empregos; SAP - Gasto Municipal de Saúde; CF - Capital Físico; $\mathrm{CH}$ - Capital Humano.

A matriz de correlação das variáveis utilizadas na pesquisa é exposta na Tabela 3, com intuito de analisar indícios de correlações elevadas entre as características dos municípios consideradas na amostra. Nota-se que não há correlações significativas identificadas, com exceção das variáveis representativas do capital físico (CF) e nível de emprego (EMP), as quais apresentaram correlação de 0.845. Além disso, as estimativas apresentaram baixo valor para o Fator de Inflação da Variância (7.01) ${ }^{10}$. Tais resultados indicam baixo indício de presença de multicolinearidade nas estimativas obtidas na presente pesquisa.

\footnotetext{
${ }^{10} \mathrm{O}$ Fator de Inflação da Variância (Variance Inflating Factor - VIF) mostra o quanto a variância dos estimadores pode estar inflada em razão da presença de multicolinearidade na amostra (Montgomery et al., 2012). Assim, valores muito elevados do VIF indicarão aumento da variância dos coeficientes, portanto menor precisão dos estimadores obtidos.
} 
Tabela 3. Matriz de Correlação das variáveis utilizadas

\begin{tabular}{lccccccc}
\hline \hline Variáveis & PIB & DENS & EMP & SAP & CF & CH & HOM \\
\hline PIB & 1000 & & & & & & \\
DENS & $-0,095$ & 1000 & & & & & \\
EMP & 0,105 & 0,344 & 1000 & & & & \\
SAP & 0,668 & $-0,213$ & $-0,009$ & 1000 & & & \\
CF & 0,103 & 0,289 & 0,845 & 0,001 & 1000 & & \\
CH & 0,167 & $-0,188$ & $-0,033$ & 0,482 & 0,045 & 1000 & \\
HOM & 0,199 & 0,286 & 0,245 & $-0,037$ & 0,216 & $-0,290$ & 1000 \\
\hline
\end{tabular}

Fonte: Resultados da pesquisa.

Nota: PIB - PIB per capita; DENS - Densidade; EMP - Empregos;

SAP - Gasto Municipal de Saúde; CF - Capital Físico; CH - Capital Humano;

HOM - Taxa de Homicídios.

\subsection{Análise exploratória de dados espaciais (AEDE)}

Para mapear as variáveis, foi feita a Análise Exploratória de Dados Espaciais (AEDE) pelo teste de autocorrelação espacial I de Moran Diferencial, discriminando os grupos de tratamento e controle. Esse teste examina a ocorrência de autocorrelação espacial com base em transformações que ocorrerem ao longo do tempo, como na construção do AMRJ ${ }^{11}$. A expressão algébrica do teste pode ser vista a seguir:

$$
I=\frac{n}{S_{0}} \frac{z^{\prime} W z}{z^{\prime} z}
$$

em que $n$ representa o número de municípios fluminenses; $S_{0}$ é a soma de todos os elementos da matriz de pesos espaciais $W$; $z$ denota o vetor com os valores da variável de interesse padronizada, observada em primeiras diferenças $\left(Y_{i t}-Y_{i(t-1)}\right)$; $W_{z}$ corresponde ao vetor com os valores médios que os vizinhos apresentam para a variável de interesse padronizada; e $W$ é a matriz ponderação espacial. Cabe ressaltar que, quando $\mathrm{W}$ é padronizada na linha, $S_{0}$ é igual a $n$.

A Tabela 4 informa que, em ambos os grupos, foram observados padrões espaciais da variável dependente e das variáveis de pareamento, fossem de similaridade (autocorrelação positiva) ou de dispersão (autocorrelação negativa).

\footnotetext{
${ }^{11}$ Para mais informações sobre o I de Moran diferencial, consultar Anselin (2016).
} 
Tabela 4. Indicadores de autocorrelação espacial diferencial por grupo de análise.

\begin{tabular}{lcccc}
\hline \hline Variável & Grupo & Matriz & Coeficiente & P-valor \\
\hline \multirow{2}{*}{ PIB } & Tratamento & $\mathrm{k}-1$ & 0,6118 & $0,0060^{* * *}$ \\
& Controle & $\mathrm{k}-4$ & $-0,1860$ & $0,0170^{* *}$ \\
$\mathrm{CF}$ & Tratamento & $\mathrm{k}-4$ & $-0,4457$ & $0,0010^{* * *}$ \\
& Controle & $\mathrm{k}-1$ & 0,4911 & $0,0040^{* * *}$ \\
CH & Tratamento & $\mathrm{k}-2$ & 0,1225 & $0,0160^{* *}$ \\
& Controle & $\mathrm{k}-2$ & 0,0383 & 0,1920 \\
EMP & Tratamento & $\mathrm{k}-4$ & $-0,4479$ & $0,0010^{* * *}$ \\
& Controle & $\mathrm{k}-1$ & 0,1555 & $0,0260^{* *}$ \\
SAP & Tratamento & $\mathrm{k}-1$ & $-0,6826$ & $0,0960^{*}$ \\
& Controle & $\mathrm{k}-2$ & 0,1117 & $0,0760^{*}$ \\
DENS & Tratamento & $\mathrm{k}-2$ & $-0,5030$ & $0,0890^{*}$ \\
& Controle & $\mathrm{k}-3$ & 0,1061 & $0,0250^{* *}$ \\
HOM & Tratamento & $\mathrm{k}-5$ & $-0,2538$ & $0,0170^{* *}$ \\
& Controle & $\mathrm{k}-2$ & 0,2367 & $0,0090^{* * *}$ \\
\hline
\end{tabular}

Fonte: Resultados da pesquisa.

Nota 1: PIB - PIB per capita; DENS - Densidade; EMP - Empregos; SAP - Gasto Municipal de Saúde; CF - Capital Físico; CH - Capital Humano; HOM - Taxa de Homicídios.

Nota 2: $k$ número de vizinhos mais próximos - remete à matriz de defasagem espacial do tipo distância geográfica. Significativo a 10\%; ** Significativo a 5\%; *** Significativo a $1 \%$.

O teste join count ou contagem de junções foi utilizado para avaliar a variável binária de interesse AMRJ. Esse teste relaciona se os municípios fluminenses que compõem o AMRJ estão autocorrelacionados espacialmente. Os municípios pertencentes ao AMRJ apresentam a terminologia "Negra" (N), enquanto os demais municípios são determinados como "Brancos" (B). Desta maneira, três são as possíveis junções (joins) a serem formadas: NN, NB e BB. As junções do tipo NN, por exemplo, correspondem ao número de municípios do AMRJ, vizinhos a municípios que também pertencem ao Arco Metropolitano.

A Tabela 5 informa que, através da matriz de ponderação espacial de cinco vizinhos mais próximos ${ }^{12}$, foram observadas 7 junções do tipo NN e 26 do tipo NB, quando os valores esperados seriam de 1,5 e 37, respectivamente. Apresentando o número observado maior que o valor esperado de junções, rejeita-se a hipótese nula do teste, sinalizando a ocorrência de padrões espaciais para as junções do tipo NN. Por sua vez, as junções do tipo NB registraram valor esperado maior que o valor observado, o

\footnotetext{
${ }^{12} \mathrm{~A}$ escolha das matrizes de defasagem espacial para os testes de Moran Diferencial e join count foi feita com base no procedimento de Baumont (2004).
} 
que remete à inexistência de padrões espaciais.

Tabela 5. Teste de autocorrelação para a variável de interesse AMRJ

\begin{tabular}{lccc}
\hline \hline Tipo de Contagem & $\begin{array}{c}\text { Número de } \\
\text { Junções }\end{array}$ & Valor Esperado & P-valor \\
\hline NN & 7 & 15.385 & $0,0000^{* * *}$ \\
NB & 26 & 369.231 & 0,9999 \\
\hline
\end{tabular}

Fonte: Resultados da pesquisa

Nota: Significativo a 10\%; ** Significativo a 5\%; *** Significativo a $1 \%$.

\subsection{AMRJ e os efeitos no PIB per capita fluminense}

Preliminarmente, optou-se por estimar o modelo de diferenças em diferenças, de maneira convencional e sem pareamento. Pela segunda coluna da Tabela 6, pode-se observar que a variável de interesse, AMRJ, não apresentou significância estatística.

Após a implementação da técnica de entropia, pela terceira coluna da Tabela 6 , é possivel inferir que o coeficiente da variável dummy AMRJ foi estatisticamente significativo. Entretanto, ao testar os resíduos dessa regressão, viu-se que apresentaram autocorrelação espacial ${ }^{13}$, não sendo possível garantir a hipótese SUTVA e a premissa de média condicional, indicando má especificação desse modelo, bem como inviabilizando a interpretação de seus resultados. Com a constatação da existência de autocorrelação espacial, é possivel apontar para a ocorrência de transbordamentos espaciais entre os municípios tratados e não tratados, tornando-se necessário estimar um SDID para encontrar de forma consistente e eficiente o efeito causal do AMRJ.

Dessa forma, a estratégia empírica adotada foi estimar a taxonomia de modelos de diferenças em diferenças espaciais, como segue: SDID-SAR, SDID-SEM, SDIDSLX, SDID-SDM e SDID-SDEM. Para definir qual desses modelos é o melhor para alcançar o objetivo proposto, em um primeiro momento, verificou-se a ausência de autocorrelação espacial nos resíduos dos modelos espaciais estimados. Entre as regressões que não apresentaram autocorrelação espacial, foi adotado, em um segundo momento, um critério de qualidade do ajuste por meio do menor valor do critério de informação AIC. Com base nesses dois passos, é possivel selecionar o melhor modelo SDID. Diante da adoção desse procedimento, verificou-se que o modelo SDID-SLX, estimado por máxima verossimilhança, é o mais adequado para estimar os efeitos do Arco Metropolitano do Rio de Janeiro sobre o crescimento econômico dos municípios fluminenses.

\footnotetext{
${ }^{13} \mathrm{O}$ valor do teste $I$ de Moran Global foi de 0,5190 , sendo significativo a $1 \%$.
} 
Tabela 6. Estimações sem controle espacial e sem pareamento, com pareamento e com controle espacial e pareamento, utilizando a dummy AMRJ como variável de interesse, e seus efeitos sobre o PIB per capita

\begin{tabular}{|c|c|c|c|c|c|c|c|}
\hline \multirow{2}{*}{ Variável } & \multirow{2}{*}{ MQO } & \multirow{2}{*}{ MQOE } & \multicolumn{5}{|c|}{ SDID } \\
\hline & & & SAR & SEM & SLX & $\mathrm{SDM}$ & SDEM \\
\hline \multirow{2}{*}{ Constante } & $2,9820 * * *$ & $4,2714^{* * *}$ & - & - & $4,2714^{* * *}$ & - & - \\
\hline & $(0,6479)$ & $(0,0136)$ & - & - & $(0,0137)$ & - & - \\
\hline \multirow{2}{*}{$\mathrm{T}$} & 0,2372 & $0,1363^{* * *}$ & $0,0696^{* * *}$ & $0,1116^{* * *}$ & $0,1372^{* * *}$ & $0,0615^{* *}$ & $0,0915^{* * *}$ \\
\hline & $(0,1617)$ & $(0,0272)$ & $(0,0230)$ & $(0,0238)$ & $(0,0275)$ & $(0,0239)$ & $(0,0282)$ \\
\hline \multirow{2}{*}{ AMRJ } & 0,0140 & $0,1900^{* * *}$ & $0,1342^{* * *}$ & $0,1452^{* * *}$ & $0,1955^{* * *}$ & $0,1168^{* * *}$ & $0,1320^{* * *}$ \\
\hline & $(0,0825)$ & $(0,0385)$ & $(0,0280)$ & $(0,0309)$ & $(0,0420)$ & $(0,0317)$ & $(0,0291)$ \\
\hline \multirow{2}{*}{$\mathrm{CF}$} & $0,3721^{* *}$ & - & - & - & - & - & - \\
\hline & $(0,1833)$ & - & - & - & - & - & - \\
\hline \multirow{2}{*}{$\mathrm{CH}$} & $-0,3874$ & - & - & - & - & - & - \\
\hline & $(0,4373)$ & - & - & - & - & - & - \\
\hline \multirow{2}{*}{ IFDM } & $-0,0041$ & - & - & - & - & - & - \\
\hline & $(0,2527)$ & - & - & - & - & - & - \\
\hline \multirow{2}{*}{ EMP } & 0,0186 & - & - & - & - & - & - \\
\hline & $(0,0333)$ & - & - & - & - & - & - \\
\hline \multirow{2}{*}{ SAP } & 0,0881 & - & - & - & - & - & - \\
\hline & $(0,0544)$ & - & - & - & - & - & - \\
\hline \multirow{2}{*}{ DENS } & $-0,0445$ & - & - & - & - & - & - \\
\hline & $(0,0326)$ & - & - & - & - & - & - \\
\hline \multirow{2}{*}{ HOM } & $0,0561^{*}$ & - & - & - & - & - & - \\
\hline & $(0,0251)$ & - & - & - & - & - & - \\
\hline \multirow{2}{*}{ WPIB } & - & - & $0,2712^{* * *}$ & - & - & $0,2956 * * *$ & - \\
\hline & - & - & $(0,0595)$ & - & - & $(0,0627)$ & - \\
\hline \multirow{2}{*}{$\mathrm{W} \varepsilon$} & - & - & - & $0,2287^{* * *}$ & - & - & $0,2854^{* * *}$ \\
\hline & - & - & - & $(0,0589)$ & - & - & $(0,0621)$ \\
\hline \multirow{2}{*}{ WAMRJ } & - & - & - & - & $-0,0173$ & 0,0388 & $0,0685^{*}$ \\
\hline & - & - & - & - & $(0,0511)$ & $(0,0350)$ & $(0,0355)$ \\
\hline \multicolumn{8}{|l|}{ Estatísticas } \\
\hline $\mathrm{R}^{2}$ & 0,2595 & 0,1423 & 0,0123 & 0,0185 & 0,1416 & 0,0087 & 0,0124 \\
\hline $\mathrm{AIC}$ & -3139762 & -3506460 & -3671450 & -3640084 & -3488621 & -3663605 & -3655643 \\
\hline Matriz & - & $\mathrm{k}-1$ & $\mathrm{k}-1$ & $\mathrm{k}-1$ & $\mathrm{k}-1$ & $\mathrm{k}-1$ & $\mathrm{k}-1$ \\
\hline $\mathrm{N}$ & 182 & 182 & 182 & 182 & 182 & 182 & 182 \\
\hline
\end{tabular}

Fonte: Resultados da pesquisa.

$\mathrm{Obs}^{1}$ :MQOE (modelo MQO estimado com pareamento por entropia); SAR (defasagem espacial da variável dependente; SEM (defasagem espacial do termo de erro); SLX (defasagem espacial das variáveis de controle); SDM (defasagem espacial da variável dependente e das variáveis de controle); SDEM (defasagem espacial do termo de erro e das variáveis de controle).

$\mathrm{Obs}^{2}$ :AMRJ - Dummy Arco Metropolitano do Rio de Janeiro; WPIB - defasagem espacial da variável dependente; $\mathrm{W} \xi$ - defasagem espacial do termo de erro; WAMRJ - defasagem espacial da dummy Arco Metropolitano do Rio de Janeiro; $k-1$ - matriz de defasagem espacial de um vizinho mais próximo. $\mathrm{Obs}^{3}$ : Desvio Padrão entre parênteses.

Nota:* Significativo a $10 \%$; ** Significativo a 5\%; *** Significativo a $1 \%$. 
Analisando a sexta coluna da Tabela 6, percebe-se que, após o controle espacial, o coeficiente da variável dummy AMRJ continuou estatisticamente significativo. Por se tratar de uma variável binária, sua interpretação, de acordo com Wooldridge (2017), requer atenção. Uma vez que a variável dependente é tida na forma de $\log (y)$, antes de empreender a análise deste coeficiente, deve ser feita a seguinte transformação:

$$
100 *\left[\exp \left(\widehat{\beta_{D A M R}}\right)-1\right]
$$

Dessa forma, o fato de um município ter pertencido ao grupo tratamento, ou seja, ter sido beneficiado pelo acesso direto ao Arco Metropolitano, contribuiu positivamente para seu crescimento econômico, percebido pelo efeito total médio de $21,6 \%$. Prováveis fundamentações para esse resultado podem ser devido ao aumento do acesso e até mesmo da conexão desses municípios à malha rodoviária estadual e federal. Nesse caso, as externalidades positivas geradas pela expansão da acessibilidade se sobrepuseram às externalidades negativas, elevando o incremento no PIB per capita dos municípios transpostos pelo AMRJ. Essa associação caminha em desacordo com o "Two-way Road Effects", uma vez que a ligação de regiões periféricas a regiões centrais apontou efeitos distributivos convergentes aos pretendidos (Holvad e Preston, 2005; SACTRA, 1999).

Caminhando na mesma direção, tem-se o trabalho de Amarante (2011), que encontrou efeitos positivos de políticas públicas brasileiras ligadas ao transporte, diretamente pela pavimentação de rodovias, sobre o crescimento econômico dos municípios catarinenses. Ademais, considerando o investimento em infraestrutura de transporte geral, Rocha e Giuberti (2007) e Gueiroz e Fernandes (2018) também apresentaram efeitos positivos para diferentes desagregações geográficas brasileiras no crescimento econômico, bem como Crescenzi e Rodríguez-Pose (2008); Cruz et al. (2010); Cigu et al. (2019) e Ke et al. (2020), que encontraram respostas semelhantes em nível de países para Europa, Brasil e China. Em direção contrária, Silva et al. (2016) constataram que o investimento em infraestrutura de transporte a partir do Programa de Aceleração do Crescimento não auxiliou o aumento da taxa média de crescimento dos PIBs estaduais brasileiros. Castro (2016), na avaliação feita para Minas Gerais, também registrou que os efeitos da pavimentação das vias rodoviárias mineiras não resultaram em crescimento econômico dos municípios contemplados.

Em termos de políticas públicas, reforça-se a cautela que o avaliador/estudioso deve ter na construção de bons contrafactuais ao grupo de tratamento. Considerando o pareamento por entropia, mostra-se que o efeito do AMRJ é positivo. Por sua vez, quando não se adota nenhum critério de pareamento, o impacto do Arco Metropolitano no crescimento econômico fluminense pode ser considerado nulo. Diante disso, o exercício empírico feito por meio do procedimento metodológico proposto foi capaz de identificar o efeito médio do tratamento, investimento no AMRJ, sobre o crescimento econômico dos municípios fluminenses, de forma consistente e eficiente. 


\section{Considerações finais}

O objetivo do presente trabalho foi identificar os efeitos do Arco Metropolitano do Rio de Janeiro (AMRJ) sobre o crescimento econômico dos municípios fluminenses entre os anos de 2007 e 2015. Para tal, foi proposto um procedimento pautado em um quase experimento que integrou a abordagem das diferenças em diferenças às técnicas espaciais e a técnica de pareamento por entropia.

Os resultados alcançados apontaram que houve impacto positivo no crescimento econômico dos municípios pertencentes ao grupo de tratamento, ou seja, dos municípios cortados pelo AMRJ. Esse resultado pode ter ocorrido devido ao fato de o AMRJ, ao aumentar a acessibilidade, reduzir os custos de transporte e integrar as regiões periféricas, com baixo custo da terra, a regiões centrais mais desenvolvidas, promovendo vantagem locacional aos municípios cortados pelo empreendimento, contribuindo para a atração de novas plantas produtivas para a região. Entre as novas plantas, é possivel citar: empresa de alimentos e agronegócio Bunge do Brasil, Rolls Royce equipamentos navais, Petrobrás, Gerdau, CSN, Usiminas, Marinha, Itaguaí Construções Navais (ICN) e Procter \& Gamble. Tais fatores contribuem no curto prazo para ampliar as oportunidades de empregos com melhores salários para a população local e incrementam o PIB per capita. No longo prazo, é possivel ter impactos na redução da desigualdade socioeconômica da região diretamente atendida pelo AMRJ. Nesse contexto, foi possivel concluir que as externalidades positivas geradas pela expansão da acessibilidade decorrente do AMRJ mais que compensaram as externalidades negativas, apontando efeitos distributivos convergentes aos pretendidos, refutando a hipótese do "Two-way Road Effects".

Em suma, este estudo contribui para a literatura econômica de avaliação de políticas públicas por levar em conta a dependência espacial presente, associada à construção do grupo de controle por meio da entropia, para estimar, de forma eficiente e consistente, o efeito causal do AMRJ. Para pesquisas futuras sobre o impacto do AMRJ, recomenda-se a análise do Arco sobre os setores da economia fluminense de maneira individual. Alternativamente, o enfoque também poderia recair sobre tópicos mais específicos como os efeitos percebidos no mercado imobiliário ou mesmo na logística/cobrança de fretes. Por fim, ressalta-se que o procedimento metodológico proposto por este trabalho pode ser utilizado para mensurar o impacto de qualquer política pública de enfoque regional exógena sobre variáveis socioeconômicas de interesse.

\section{Referências}

Agénor, P.-R. e Moreno-Dodson, B. (2006). Public Infrastructure And Growth : New Channels And Policy Implications. The World Bank.

Amarante, A. (2011). Ensaios sobre economia regional e urbana. Doutorado em eco- 
nomia aplicada, Universidade Federal do Rio Grande do Sul, Programa de PósGraduação em Economia, Porto Alegre.

Anselin, L. (1995). Local indicators of spatial association-LISA. Geographical analysis, 27(2):93-115.

Anselin, L. (2016). Geoda 1.8.14 user's guide. University of Chicago.

Aschauer, D. A. (1989). Is public expenditure productive? Journal of Monetary Economics, 23(2):177-200.

Badalyan, G., Herzfeld, T., e Rajcaniova, M. (2014). Transport infrastructure and economic growth: Panel data approach for Armenia, Georgia and Turkey. Review of Agricultural and Applied Economics, 17(2):22-31.

Banister, D. e Berechman, Y. (2001). Transport investment and the promotion of economic growth. Journal of transport geography, 9(3):209-218.

Bank, W. (2006). Infrastructure at the crossroads: lessons from 20 years of World Bank experience. The World Bank, Washington, DC.

Barro, R. J. (1996). Determinants of economic growth: A cross-country empirical study. Working Paper 5698, National Bureau of Economic Research.

Becker, S. O. e Ichino, A. (2002). Estimation of average treatment effects based on propensity scores. The stata journal, 2(4):358-377.

Berechman, J. (2009). The evaluation of transportation investment projects. Routledge, New York.

Brasil (2011). Plano Diretor do Arco Metropolitano. Secretaria Estadual de Obras e Secretaria de Desenvolvimento Econômico. Rio de Janeiro.

Bueno, A. e Sarti, F. (2019). Os impactos de uma elevação dos investimentos em infraestrutura no Brasil: uma análise referente a 2015. In: Anais do XVIII Seminário sobre Economia Mineira, Diamantina, MG.

Cabral, M. V. F. (2016). Avaliação do impacto do INFOCRIM sobre as taxas de homicídios dos municípios paulistas: uma aplicação do método de diferenças em diferenças espacial. Doutorado em economia, Universidade Federal de Juiz de Fora, Juiz de Fora.

Cameron, A. C. e Trivedi, P. K. (2005). Microeconometrics: methods and applications. Cambridge University Press, Cambridge.

Campos Neto, C. A. d. S. (2014). Investimentos na infraestrutura de transportes: Avaliação do período 2002-2003 e perspectivas para 2014-2016. Texto para Discussão 2014, Instituto de Pesquisa Econômica Aplicada (IPEA), Brasília. 
Castro, L. S. (2016). Crescimento Econômico e Infraestrutura: O Impacto do ProAcesso em Minas Gerais. Doutorado em economia aplicada, Universidade Federal de Viçosa, Programa de Pós-Graduação em Economia Aplicada, Viçosa.

Chagas, A. L., Azzoni, C. R., e Almeida, A. N. (2016). A spatial difference-in-differences analysis of the impact of sugarcane production on respiratory diseases. Regional Science and Urban Economics, 59:24-36.

Cigu, E., Agheorghiesei, D. T., Toader, E., et al. (2019). Transport infrastructure development, public performance and long-run economic growth: a case study for the Eu-28 countries. Sustainability, 11(1):67.

Crescenzi, R. e Rodríguez-Pose, A. (2008). Infrastructure endowment and investment as determinants of regional growth in the European Union. EIB Papers, 13(2):62101.

Cruz, A. C., Teixeira, E. C., e Braga, M. J. (2010). Os efeitos dos gastos públicos em infraestrutura e em capital humano no crescimento econômico e na redução da pobreza no Brasil. Revista Economia, 11(4):163-185.

Dias, L. R. e Simões, R. F. (2012). Infraestrutura de transportes e desenvolvimento econômico: um estudo do PROACESSO em Minas Gerais. In: Anais do XV Seminário sobre Economia Mineira, Diamantina, MG.

Dubé, J., Legros, D., Thériault, M., e Des Rosiers, F. (2014). A spatial difference-indifferences estimator to evaluate the effect of change in public mass transit systems on house prices. Transportation Research Part B: Methodological, 64:24-40.

Ferreira, P. C. G. e Malliagros, T. G. (1996a). Impactos Produtivos da Infraestrutura no Brasil, 1950-1995. Pesquisa e Planejamento Econômico, 28(2):315-338.

Ferreira, P. C. G. e Malliagros, T. G. (1996b). Investimento em infraestrutura no Brasil: fatos estilizados e relações de longo prazo. Pesquisa e Planejamento Econômico, 26(2):231-252.

FIRJAN (2008). Avaliação dos Impactos Logísticos e Socioeconômicos da Implantação do Arco Metropolitano do Rio de Janeiro. Federação das Indústrias do Estado do Rio de Janeiro.

François, P. (1955). Note sur la notion de pôle de croissance. Economc Apliqué, 7:307320.

Fujita, M., Krugman, P. R., e Venables, A. (1999). The spatial economy: Cities, regions, and international trade. MIT press, Cambridge, Massachusetts.

Fujita, M., Krugman, P. R., e Venables, A. (2002). Economia Espacial: urbanização, prosperidade econômica e desenvolvimento humano no mundo. Editoria Futura, São Paulo. 
Guimarães, P. M. (2012). Dois Ensaios Sobre a Questão da Convergência de Renda no Brasil. Mestrado em economia aplicada, Universidade Federal de Juiz de Fora, Programa de Pós-graduação em Economia Aplicada, Juiz de Fora.

Hainmueller, J. (2012). Entropy balancing for causal effects. Political analysis, Página 25-46.

Hirschman, A. (1961). Estratégia do desenvolvimento econômico. Fundo de Cultura, Rio de Janeiro.

Holvad, T. e Preston, J. (2005). Road transport investment projects and additional economic benefits. 45th Congress of the European Regional Science Association. Amsterdam, The Netherlands, Louvain-la-Neuve.

Ke, X., Lin, J. Y., Fu, C., e Wang, Y. (2020). Transport Infrastructure Development and Economic Growth in China: Recent Evidence from Dynamic Panel System-GMM Analysis. Sustainability, 12(14):5618.

Kelejian, H. H. e Robinson, D. P. (1997). Infrastructure productivity estimation and its underlying econometric specifications: a sensitivity analysis. Papers in Regional Science, 76(1):115-131.

Khan, T. (1998). A violência brasileira. Conjuntura Criminal, 1(3).

Kroth, D. C. e Dias, J. (2012). Os efeitos dos investimentos público e privado em capitais físico e humano sobre o produto per capita dos municípios da região sul: uma análise em painéis de dados dinâmicos. Nova Economia, 22(3):621-649.

Krugman, P. R. (1991). Geography and trade. MIT press, Cambridge.

Lesage, J. e K., P. R. (2009). Introduction to Spatial Econometrics. CRC Press.

Lösch, A. (1954). Economics of location.

Lucas Jr, R. E. (1988). On the mechanics of economic development. Journal of monetary economics, 22(1):3-42.

Malliagros, T. G. (1997). O impacto da infraestrutura sobre o crescimento da produtividade do setor privado e do produto brasileiro. Mestrado em economia, Fundação Getúlio Vargas, Escola de Pós-Graduação em Economia, Rio de Janeiro.

Mankiw, N. G., Romer, D., e Weil, D. N. (1992). A contribution to the empirics of economic growth. The Quarterly Journal of Economics, 107(2):407-437.

Montgomery, D. C., Peck, E. A., e Vining, G. G. (2012). Introduction to linear regression analysis. John Wiley \& Sons, New York.

Moran, P. A. (1948). The interpretation of statistical maps. Journal of the Royal Statistical Society: Series B (Methodological), 10(2):243-251. 
Munnell, A. H. et al. (1992). Why has productivity growth declined? productivity and public investment. New England economic review, (Jan):3-22.

Myrdal, G. (1957). Economic theory and under-developed regions. Duckworth, London.

Preston, J. (2001). Integrating transport with socio-economic activity - a research agenda for the new millennium. Journal of Transport Geography, 9(1):13-24.

Puga, D. (2001). European Regional Policies in Light of Recent Location Theories. CEPR Discussion Papers 2767, C.E.P.R. Discussion Papers.

Queiroz, S. L. e Fernandes, E. A. (2018). A infraestrutura de transporte rodoviário e o crescimento econômico brasileiro. Revista Estudo \& Debate, 25(2).

Rocha, F. e Giuberti, A. C. (2007). Composição do gasto público e crescimento econômico. Economia Aplicada, 11:463-485.

Rubin, D. B. (1977). Assignment to treatment group on the basis of a covariate. Journal of educational Statistics, 2(1):1-26.

Ruiz, R. M. (2006). Políticas regionais na nova geografia econôomica, Capítulo 6, Página 144-173. Editora UFMG, Belo Horizonte.

SACTRA (1999). Standing Advisory Committee on Trunk Road Assessment. Transport and the Economy. DETR, Londres.

Shah, A. (1992). Dynamics of public infrastructure, industrial productivity and profitability. The Review of Economics and Statistics, Página 28-36.

Silva, G. J. C. d., Martins, H. E. d. P., e Neder, H. D. (2016). Investimentos em infraestrutura de transportes e desigualdades regionais no Brasil. Brazilian Journal of Political Economy, 36:840-863.

Solow, R. M. (1956). A contribution to the theory of economic growth. The quarterly journal of economics, 70(1):65-94.

Sturm, J.-E., Jacobs, J., e Groote, P. (1999). Output effects of infrastructure investment in the Netherlands, 1853-1913. Journal of Macroeconomics, 21(2):355-380.

Von Thünen, J. H. (1966). The isolated state. Primeira Edição 1826. Pergamon Press, Oxford, 6 edition.

Wooldridge, J. M. (2017). Introdução à econometria: uma abordagem moderna. Pioneira Thomson Learning, São Paulo, 6 edition.

(ल) Este artigo está licenciado com uma CC BY 4.0 license. 


\section{Appendix}

Guadro A1. Resumo dos trabalhos empíricos sobre a avaliação de investimentos em infraestrutura de transportes

\begin{tabular}{|c|c|c|c|}
\hline Autores & Relação Analisada & Metodologia & Principais Conclusões \\
\hline (Shah, 1992) & $\begin{array}{l}\text { Investimento público em infraestrutura } \\
\text { no México entre } 1970 \text { e } 1987\end{array}$ & $\begin{array}{l}\text { Equilíbrio } \\
\text { Restrito }\end{array}$ & $\begin{array}{l}\mathrm{O} \text { impacto da infraestrutura de trans- } \\
\text { porte foi positivo, apesar de pequeno. }\end{array}$ \\
\hline $\begin{array}{l}\text { (Ferreira e } \\
\text { Malliagros, } \\
\text { 1996b; Malli- } \\
\text { agros, 1997; } \\
\text { Ferreira e } \\
\text { Malliagros, } \\
\text { 1996a) }\end{array}$ & $\begin{array}{l}\text { A trajetória dos investimentos em infra- } \\
\text { estrutura de transportes no Brasil e seus } \\
\text { efeitos no PIB do país }\end{array}$ & $\begin{array}{l}\text { Modelos de Ve- } \\
\text { tores de Coin- } \\
\text { tegração }\end{array}$ & $\begin{array}{l}\text { Os investimentos afetaram significativa- } \\
\text { mente o PIB brasileiro, dada a elastici- } \\
\text { dade de renda. O baixo crescimento en- } \\
\text { tre } 1970 \text { e } 1993 \text { se deu em função da } \\
\text { queda desses investimentos. }\end{array}$ \\
\hline $\begin{array}{l}\text { (Sturm et al., } \\
\text { 1999) }\end{array}$ & $\begin{array}{l}\text { O investimento em infraestrutura de } \\
\text { transporte no PIB holandês entre } 1853 \\
\text { e } 1913\end{array}$ & $\begin{array}{l}\text { Vetores Au- } \\
\text { toregressivos } \\
\text { (VAR) }\end{array}$ & $\begin{array}{l}\text { Nos curto e médio prazos, houve impac- } \\
\text { tos positivos sobre o PIB. }\end{array}$ \\
\hline $\begin{array}{l}\text { (Rocha e Giu- } \\
\text { berti, 2007) }\end{array}$ & $\begin{array}{l}\text { Os componentes do gasto público e o } \\
\text { crescimento econômico de longo prazo } \\
\text { em estados brasileiros }\end{array}$ & $\begin{array}{l}\text { Modelo de } \\
\text { Efeitos Fixos }\end{array}$ & $\begin{array}{l}\text { As despesas com infraestrutura de } \\
\text { transporte apresentaram significância } \\
\text { estatística e coeficientes positivos. }\end{array}$ \\
\hline $\begin{array}{l}\text { (Crescenzi } \\
\text { Rodríguez- } \\
\text { Pose, 2008) }\end{array}$ & $\begin{array}{l}\text { O investimento em infraestrutura, } \\
\text { transportes, e o crescimento/desenvol- } \\
\text { vimento regional na união europeia, no } \\
\text { período entre } 1990 \text { e } 2003 \text {. }\end{array}$ & $\begin{array}{l}\text { Modelagem de } \\
\text { Dados em Pai- } \\
\text { nel }\end{array}$ & $\begin{array}{l}\text { Os investimentos em infraestrutura de } \\
\text { transporte podem beneficiar regiões cen- } \\
\text { tralizadas em razão das periféricas }\end{array}$ \\
\hline $\begin{array}{l}\text { (Cruz et al., } \\
2010)\end{array}$ & $\begin{array}{l}\text { Efeitos dos gastos públicos em infra- } \\
\text { estrutura no crescimento econômico e } \\
\text { na redução da pobreza no Brasil, entre } \\
1980 \text { e } 2007 \text {. }\end{array}$ & $\begin{array}{l}\text { Equações Si- } \\
\text { multâneas }\end{array}$ & $\begin{array}{l}\text { Comprovou-se a eficiência dos gastos } \\
\text { públicos em educação, saúde, estradas } \\
\text { e energia. De maneira geral, os avanços } \\
\text { elevaram a renda per capita e a produ- } \\
\text { tividade total dos fatores, gerando cres- } \\
\text { cimento econômico com redução da po- } \\
\text { breza. }\end{array}$ \\
\hline $\begin{array}{l}\text { (Amarante, } \\
2011) \text { ) }\end{array}$ & $\begin{array}{l}\text { Impacto da pavimentação das BR 101 e } \\
\text { BR } 116 \text { nos municípios de Santa Cata- } \\
\text { rina entre } 1970 \text { e } 2006\end{array}$ & $\begin{array}{l}\text { Modelagem de } \\
\text { Dados em Pai- } \\
\text { nel }\end{array}$ & $\begin{array}{l}\text { Em média, houve maior crescimento } \\
\text { econômico nos municípios beneficiados } \\
\text { pela pavimentação ao longo do período. }\end{array}$ \\
\hline $\begin{array}{l}\text { (Guimarães, } \\
\text { 2012) }\end{array}$ & $\begin{array}{l}\text { Infraestrutura e convergência de renda } \\
\text { no Brasil, entre } 1999 \text { e } 2005\end{array}$ & $\begin{array}{l}\text { Modelagem de } \\
\text { Dados em Pai- } \\
\text { nel }\end{array}$ & $\begin{array}{l}\text { Em média, houve maior crescimento } \\
\text { econômico nos municípios beneficiados } \\
\text { pela pavimentação ao longo do período. }\end{array}$ \\
\hline $\begin{array}{l}\text { (Badalyan } \\
\text { et al., 2014) }\end{array}$ & $\begin{array}{l}\text { Infraestrutura de transporte, o investi- } \\
\text { mento em infraestrutura e o crescimento } \\
\text { econômico na Armênia, Turquia e Geor- } \\
\text { gia entre } 1982 \text { e } 2010\end{array}$ & $\begin{array}{l}\text { Modelagem de } \\
\text { Dados em Pai- } \\
\text { nel }\end{array}$ & $\begin{array}{l}\text { Existência de causalidade bidirecional } \\
\text { entre crescimento econômico e investi- } \\
\text { mento em infraestrutura de transporte } \\
\text { no curto e no longo prazo. }\end{array}$ \\
\hline (Castro, 2016) & $\begin{array}{l}\text { Programa de Pavimentação de Ligações e } \\
\text { Acessos aos Municípios (ProAcesso) em } \\
\text { municipios de Minas Gerais entre } 2000 \\
\text { e } 2010\end{array}$ & $\begin{array}{l}\text { Método de } \\
\text { diferenças- } \\
\text { em-diferenças } \\
\text { espacial com } \\
\text { técnicas de } \\
\text { pareamento }\end{array}$ & $\begin{array}{l}\text { Não se verificou maior crescimento } \\
\text { econômico causado pelo fato de um mu- } \\
\text { nicípio ser atendido pelo ProAcesso. }\end{array}$ \\
\hline $\begin{array}{l}\text { (Silva et al., } \\
\text { 2016) }\end{array}$ & $\begin{array}{l}\text { Efeitos dos investimentos em infraes- } \\
\text { trutura de transporte, realizados pelo } \\
\text { Programa de Aceleração do Crescimento } \\
\text { (PAC) sobre a dinâmica regional brasi- } \\
\text { leira }\end{array}$ & $\begin{array}{l}\text { Modelagem } \\
\text { de Dados em } \\
\text { Painel e boots- } \\
\text { trapping }\end{array}$ & $\begin{array}{l}\text { O PAC não auxiliou o aumento da taxa } \\
\text { média de crescimento dos PIBs estadu- } \\
\text { ais brasileiros e nem reduziu desigual- } \\
\text { dades regionais existentes. }\end{array}$ \\
\hline $\begin{array}{l}\text { (Queiroz e Fer- } \\
\text { nandes, 2018) }\end{array}$ & $\begin{array}{l}\text { Investimentos em infraestrutura de } \\
\text { transportes e o crescimento econômico } \\
\text { brasileiro, entre os anos de } 2008 \text { e } 2013\end{array}$ & $\begin{array}{l}\text { Modelagem de } \\
\text { Dados em Pai- } \\
\text { nel }\end{array}$ & $\begin{array}{l}\text { Uma maior oferta de conexões rodoviá- } \\
\text { rias, associada aos spillovers de investi- } \\
\text { mento em infraestrutura de transporte, } \\
\text { afetaram positivamente o crescimento } \\
\text { econômico brasileiro. }\end{array}$ \\
\hline $\begin{array}{l}\text { (Cigu et al., } \\
2019)\end{array}$ & $\begin{array}{l}\text { Ligação entre a infraestrutura de trans- } \\
\text { porte e o desempenho econômico em paí- } \\
\text { ses } 28 \text { países da Europa, entre } 2000 \text { e } \\
2014\end{array}$ & $\begin{array}{l}\text { Modelagem de } \\
\text { Dados em Pai- } \\
\text { nel }\end{array}$ & $\begin{array}{l}\text { Houveram efeitos significativos dos } \\
\text { componentes da infraestrutura de } \\
\text { transporte no desempenho econômico, } \\
\text { mesmo após o controle de fatores insti- } \\
\text { tucionais. }\end{array}$ \\
\hline $\begin{array}{l}\text { (Ke et al., } \\
2020)\end{array}$ & $\begin{array}{l}\text { Investimentos em infraestrutura de } \\
\text { transporte e o crescimento econômico } \\
\text { regional na China, no período de } 2007 \text { - } \\
2015\end{array}$ & $\begin{array}{l}\text { Sistema de } \\
\text { dados de pai- } \\
\text { nel dinâmico } \\
(\text { GMM) }\end{array}$ & $\begin{array}{l}\text { A melhoria da qualidade das estradas e } \\
\text { das ferrovias, interligada a atualização } \\
\text { estrutural da infraestrutura de trans- } \\
\text { porte, contribuíram significativamente } \\
\text { para o crescimento econômico chinês. }\end{array}$ \\
\hline
\end{tabular}

